\title{
Factors influencing the choice of surgery as a career by pre- registration interns
}

\author{
*Lawal TA, Afolabi AO
}

Department of Surgery, University of Ibadan, Ibadan and University College Hospital, Ibadan, Nigeria

\begin{abstract}
Background: The dwindling interest in surgery and surgical specialties raises the fears that the surgical man-power requirements of the society may not be met adequately in coming years. There is a need to explore ways of stimulating interest in surgery in order to forestall this.

Objective: To identify factors that influence or predict the choice of surgery as a career by interns.

Methods: A descriptive cross-sectional study of 271 interns was conducted using structured self administered questionnaires. The data obtained included demographic details, details of internship rotations, choice of specialty, reasons for nonconsideration of surgery and if the interns had role models, staff advisers and first degree relatives who were surgeons. Data were analysed using descriptive and inferential statistics (SPSS software) with the level of significance at $\mathrm{p}<0.05$.

Results: There were 163 (60.1\%) males and 108 (39.9\%) females with a mean age of 25.8 years. The majority (97\%) wished to commence residency training soon after internship; surgery (37.6\%), and internal medicine $(22.4 \%)$ were the most popular choices. Reasons for non-consideration of surgery included: stressful (46.1\%), future family plans (41.3\%) and difficult training (18.1\%). Males were more likely to choose surgery than females $(52.1 \%$ vs. $13.0 \%$, p < 0.001$)$. Married interns were less likely to choose surgery compared to their single colleagues $(0 \%$ vs. $37.5 \%, \mathrm{p}=0.042)$. Having surgeons as role models, staff advisers or first degree relatives were significantly associated with selecting a career in surgery.

Conclusion: Gender, marital status, having surgeons as role models, staff advisers or first degree relatives in medical school are significant factors influencing the choice of a career in surgery.

Keywords: career choice; interns; surgery; surgical specialties

African Health Sciences 2013; 13(3): 814 - 819 http:/ /dx.doi.org/10.4314/ahs.v13i3.42
\end{abstract}

\section{Introduction}

Internship is a crucial phase in the life of a medical doctor. In ex-British commonwealth countries, it serves as a period between medical school and residency training when a young doctor is exposed to a greater interaction with older colleagues, specialists and patients at a level beyond what was encountered while in medical school. ${ }^{1}$ It is often at this stage that ideas about the choice of specialty are cemented and life changing decisions made.

Recently, changes have occurred in the organisation of postgraduate training worldwide, partly because of newer regulations about working time directives but also because greater structuring and coupling between trainers and trainees are required in order to maximise the period of residency training. ${ }^{2,3}$

\author{
*Corresponding author: \\ Dr. Taiwo A. Lawal \\ Department of Surgery \\ University of Ibadan \\ PMB 5017 \\ Ibadan, Nigeria 200212 \\ Telephone: +2348069614811 \\ Email: taiwo.lawal@hotmail.com
}

Furthermore, lifestyle issues have become more important than before in guiding potential residents to make a choice of career. ${ }^{4-6}$ As a result, surgery has faced greater fears than most specialties about being able to fill the required pool with the best available hands. ${ }^{7}$ This is further reinforced by the declining popularity of general surgery and other surgical specialties in North America in recent years. ${ }^{7,8}$ The long term effect of this, if not corrected, is that the deficits in surgical workforce will become more pronounced and challenging to balance as the population ages. ${ }^{8}$ Previous studies conducted have tended to pool together medical students and interns, without consideration of possible differences in characteristics between these two groups. ${ }^{4}$ Furthermore, the choice of specialty training as a medical student may not be consistent with the decision taken at a later stage. ${ }^{?}$

Understanding the major cause of this decline in interest will be feasible if we are able to elucidate the factors that guide young medical graduates, such as interns, to choose a career in surgery. However, there is paucity of knowledge of these factors in our interns. 
We, therefore, conducted this study to identify the factors that influence interns in making a choice of surgery as their intended area of specialisation, and find the predictors of choosing a career in surgery by an intern.

\section{Methods}

The study site - University College Hospital, Ibadan - is an 850 bedded tertiary hospital located in the heart of Ibadan, Nigeria. The hospital, a federal government funded institution, was established in 1957. There are over 55 departments in the hospital and it is accredited by the national regulatory agencies to train a maximum of 160 interns annually. The internship is mandatory for all new medical graduates before inclusion in the register of the Nigerian Medical and Dental Council, i.e. a prelude to obtaining a full license to practise medicine or dentistry in the country. The interns rotate through four departments namely; medicine, surgery, paediatrics and obstetrics and gynaecology spending three months in each posting. While in surgery, they rotate through the available divisions: gastrointestinal surgery, hepatobiliary and endocrine surgery, oncology surgery, paediatric surgery, plastic and reconstructive surgery, urology, cardiovascular and thoracic surgery, orthopaedics and trauma and neurosurgery.

A cross-sectional study was conducted at a major university teaching hospital in southern Nigeria between August 2003 and July 2008. Structured questionnaires were administered to 310 randomly selected interns over the period. An estimated sample size of 230 interns was arrived at using a prevalence of $18.1 \%$ from a previous study, a power of $90 \%$ and a precision (d) of 5\%. At an employment rate of 60 interns per year (minimum as at 2002), it was estimated that the study would take five years. A total of $271(87.4 \%)$ interns returned the anonymised self administered questionnaires.

The data obtained included demographic data, rotations done prior to the interview, present rotation, choice of specialty and sub-specialty training and reasons for non consideration of surgery as a career choice. We also obtained data about if the interns had role models and staff advisers while in the medical school and if those were surgeons; and if they had first degree relatives who were surgeons.

Data were analysed using descriptive and inferential statistics with the Statistical Package for

African Health Sciences Vol 13 Issue 3 September 2013 the Social Sciences (SPSS) version 19 software. Univariate analysis was done and results presented as proportions and percentages. Bivariate analysis using chi square statistics was performed to identify the influence of gender, role models, staff advisers and surgeon first degree relatives on the choice of surgery as a future career pathway. Multinomial logistic regression was conducted to identify independent predictors of young medical graduates selecting surgery as a career choice. The level of statistical significance was set at a p-value less than 0.05 .

\section{Results}

A total of 271 interns participated in the study, consisting of $163(60.1 \%)$ males and 108 (39.9\%) females. The mean age of the study participants was $25.8 \pm 1.2$ years and the majority $(264,97.4 \%)$ were single. A total of $71(26.2 \%)$ had completed their surgery rotation at the time of the study. The present rotation of the interns at that time is as shown in table 1.

Table 1: Present rotation of the interns at the time the study was conducted

\begin{tabular}{|c|c|}
\hline Rotation & Frequency $(\%)$ \\
\hline Surgery & $79(29.2)$ \\
\hline Internal Medicine & $55(20.3)$ \\
\hline Paediatrics & $63(23.2)$ \\
\hline Obstetrics and Gynaecology & $74(27.3)$ \\
\hline Total & $271(100.0)$ \\
\hline
\end{tabular}

The majority $(263,97.0 \%)$ intended to commence residency training after their internship. Surgery, accounting for $37.6 \%$, was the leading choice of specialty by the interns (table 2). Of the 99 who wished to become surgeons, orthopaedics and trauma $(33,33.3 \%)$ and cardiothoracic surgery (29, $29.3 \%$ ) were the most popular choices. The other sub-specialties were: paediatric surgery $(13,13.1 \%)$, neurosurgery $(7,7.1 \%)$, general surgery $(6,6.1 \%)$, urology $(6,6.1 \%)$, plastic surgery $(3,3.0 \%)$ while two were undecided. The reasons given for non consideration of surgery as a career choice included: that "surgery is stressful" as a career choice (125, $46.1 \%)$, that "the training is difficult" (49, 18.1\%), and that surgery would not "accommodate future family plans" (112, 41.3\%).

A total of $160(59.0 \%)$ participants had a role model while in medical school. The role model 
was a surgeon in $65(40.6 \%)$ of this subset of participants. One hundred and forty two of the interns $(52.4 \%)$ had a staff adviser while in school with $52(36.6 \%)$ of those being surgeons. Twentysix participants had a first degree relative who was a surgeon.

Table 2: Choice of specialty among the interns

\begin{tabular}{ll}
\hline Specialty & Frequency (\%) \\
\hline Surgery & $99(37.6)$ \\
Internal Medicine & $59(22.4)$ \\
Paediatrics & $26(9.9)$ \\
Obstetrics and Gynaecology & $24(9.1)$ \\
Public Health & $17(6.5)$ \\
Other specialties & $31(11.8)$ \\
Undecided & $7(2.7)$ \\
Total & $\mathbf{2 6 3 ( 1 0 0 . 0 )}$ \\
\hline
\end{tabular}

The analysis of the influence of demographic characteristics on the selection of surgery as a career choice showed that 85 out of $163(52.1 \%)$ males selected surgery compared with 14 out of 108 $(13.0 \%)$ females $(p<0.001)$. None of those who were married (all females) selected surgery as a choice for career progression compared with 99 out of $264(37.5 \%)$ interns who were single $(p=0.042)$. Among the 71 interns who had completed their surgical rotation prior to the study, $32(45.1 \%)$ opted for surgery as a career choice while 67 of the 200 $(33.5 \%)$ who had not completed their surgical posting had a similar choice $(\mathrm{p}=0.082)$. Comparing the choice of surgery among interns in different rotations at the time of the study, surgery was the choice of $34.2 \%(27 / 79)$ of those in surgery, $43.6 \%$ $(24 / 55)$ of those in internal medicine, $44.4 \%$ (28/ 63) of those in paediatrics and $27.0 \%(20 / 74)$ of those rotating through obstetrics and gynaecology $(\mathrm{p}=0.113)$.

Of the 65 participating interns who had surgeons as role models while in medical school, 42 $(64.6 \%)$ hoped to pursue a career in surgery. Comparatively, 10 of 95 (10.5\%) interns whose role models were not surgeons selected surgery as a career choice $(\mathrm{p}<0.001)$. Among the interns whose staff advisers in school were surgeons, 27 of $52(51.9 \%)$ opted for surgery compared with 20 out of 90 $(22.2 \%)$ whose staff advisers were not surgeons $(\mathrm{p}$ $<0.001)$. A total of 17 interns out of $26(65.4 \%)$ who had a surgeon first degree relative hope to become surgeons while 82 of 245 (33.5\%) who do not have surgeons as first degree relatives selected surgery as their choice $(p=0.001)$.

Using a multinomial logistic regression model performed step-wise, gender and having a surgeon as a role model were found to be significant independent predictors of selecting a career in surgery (table 3). Males were four times more likely than females to select surgery $(95 \%$ Confidence Interval of $1.16-14.22)$. Interns who had surgeons as their role models while in medical school were nine times more likely to want to become surgeons than their counterparts who had others as role models (95\% Confidence Interval of $2.89-30.77$ ).

Table 3: Multiple logistic regression of the factors that influence the choice of career in surgery of the interns (reference category - choice not surgery)

\begin{tabular}{lllll}
\hline Variables & Categories & $\begin{array}{c}\text { Odds Ratio } \\
(\operatorname{exp~B)}\end{array}$ & p- value & $\begin{array}{l}\mathbf{9 5 \%} \text { Confidence } \\
\text { Interval(of Odds Ratio) }\end{array}$ \\
\hline Gender & $\begin{array}{l}\text { Male } \\
\text { Female }\end{array}$ & 4.062 & $\mathbf{0 . 0 2 8}$ & $1.160-14.219$ \\
Marital Status & $\begin{array}{l}\text { Single } \\
\text { Married }\end{array}$ & 1540344.264 & NE & 1540344.264 \\
Surgeon as role model & $\begin{array}{l}\text { Yes } \\
\text { No }\end{array}$ & 9.430 & $\mathbf{0 . 0 0 0}$ & $2.890-30.773$ \\
Surgeon as staff adviser & $\begin{array}{l}\text { Yes } \\
\text { No }\end{array}$ & 1.587 & 0.449 & $0.480-5.240$ \\
Surgeon 1st degree relative & Yes & $1.021 \mathrm{E} 8$ & $\mathrm{NE}$ & $\mathrm{NE}$ \\
\hline
\end{tabular}

NE - Not estimated since the output was redundant in the model 


\section{Discussion}

The choice of specialty by a young medical graduate is a decision that is laden with lots of dilemma. This is made particularly more difficult in countries where the decision has to be made quite soon after medical school. In ex-British commonwealth countries, the old convention was for interns to spend a period of time in practice, e.g. as medical officers and senior house officers, without necessarily committing to a specialty. ${ }^{2}$ This, however, has changed and most training programmes in those countries require that young doctors make a choice about their specialty and subspecialty of training before entering the system or very early in the programme. In this study, 97\% of the interns wish to commence residency training sometimes soon after the internship year. This proportion is higher than $80 \%$ reported from the same region in a survey of 167 senior medical students and interns regarding their willingness to specialise. ${ }^{4}$ The higher figure in the present study may be because it was conducted purely on interns unlike the latter study that recruited medical students as well. It is probable that as medical students, some may not have made the decision to specialise. The proportion is also higher than the $82.9 \%$ documented in a study conducted on 105 interns from the same region 11 years ago. ${ }^{1}$ The recent changes in postgraduate medical education and socioeconomic considerations may be responsible for the difference between the studies.

Surgery was the most popular choice of specialty by the interns in this study. This is similar to the findings by Abioye et al. ${ }^{4}$ in a survey where surgery was the leading specialty of choice for both medical students and interns in Lagos, Nigeria. It also is in agreement with the outcome of the study by Scott et al. ${ }^{8}$ on 2168 Canadian medical students of which nearly $80 \%$ indicated a primary or secondary interest in surgery. Factors that have been noted to contribute to making surgery remain popular despite the declining proportion of those interested in surgery overall include career rewards such as income, perceived social prestige, job opportunities and scope of practice of surgery and surgical specialties. ${ }^{7,810-12}$ Interest in general surgery, plastic surgery and urology in the present study is abysmally poor compared to the overwhelming predilection the interns have for careers in orthopaedics and trauma surgery as well as cardiothoracic surgery. This finding also confirms the global trend in less interest in general surgery as a career choice. ${ }^{7}$ The reasons that have been suggested include the perception that general surgery as a career choice has limited scope of specialty expertise and differential diagnostic skills are underemphasized. ${ }^{7}$ The lifestyle of attending general surgeons as well as their residents and excessive workload issues have, additionally, been reported as deterrents to selecting a career in general surgery. ${ }^{11,12}$ General surgery, and to a lesser extent other surgical specialties, are viewed as professions that confer poor control over lifestyle both during and after residency training. ${ }^{12}$ The finding from the present study, however, contrasts with the study by Yusufu et al. ${ }^{13}$ conducted on 68 interns in Zaria, Nigeria, in which $26 \%$ (6 out of 23 ) of the respondents who opted for surgery wished to become general surgeons. The difference between the studies may be due to the larger sample recruited in the present study (271 vs. 68).

Female interns in this study were less likely to select a career in surgery. The female interns who were married were most unlikely to wish to become surgeons. Male gender on the other hand was an independent predictor of selecting a career in surgery. This mirrors the general finding in the medical education literature with females increasingly less likely to select surgery as career choice..$^{6,10,14,15}$ Many factors have been documented to constitute hindrances to females selecting careers in surgery. These include difficulty balancing career with domestic responsibilities, lack of flexibility in career structure and an overwhelming lack of female role models in the surgical field. ${ }^{16,17}$ These challenges are corroborated by the finding in this study that many of those who did not select surgery as a choice gave reasons for non-consideration of surgery to include surgery being a stressful career choice and that it was unlikely to accommodate their future family plans. Females tend to be discouraged from a career in surgery because of the assumption that it is not as compatible with childbearing or having a happy family life as are other specialties such as internal medicine, family medicine etc. ${ }^{18-20}$

Mentoring is an important component of higher education, which has considerable influence on shaping the minds of university students. Having a surgeon as a role model, a staff adviser while in medical school or a first degree relative was associated with interns in this study selecting a future in surgery. Mentoring will appear to be quite an important factor in mentees taking on a surgical specialty based on positive interactions with their surgeon role model, staff adviser or family member. 
Furthermore, it has been shown that medical students who select surgery, early or even later, in medical school tend to maintain this choice of specialty after graduation in a way that is not seen with most other specialties. ${ }^{9} 21$ One of the deterrents reported by females who do not choose a career in surgery is the lack of a role model in that specialty. ${ }^{10,17}$

One of the limitations of this study is the possible influence the lifestyle of surgeons based in the hospital where the study was conducted may have on the perception that interns have on what awaits them if they select a career in surgery. The surgeons and gynaecologists in the hospital apparently enjoy the most lucrative of private practice with added income, which may have contributed to a positive impression on the minds of these interns. The five year duration of the cross-sectional study is another limitation that may also have influenced the result since the characteristics of the interns on an annual basis was not evaluated, and bias might have occurred when interns got to know about the contents of the questionnaire before participating.

\section{Conclusion}

Surgery is still the most popular choice of postgraduate training by interns. Male gender, single status, having a surgeon as a role model or staff adviser while in medical school and having a surgeon as a first degree family member are associated with selecting a career in surgery or surgical subspecialties by interns. Male gender and having a surgeon as a role model were significant independent predictors of a future career in surgery.

\section{References}

1. Odusanya OO, Nwawolo CC. Career aspirations of house officers in Lagos, Nigeria. Med Educ 2001; 35(5): 482-487.

2. Brownrigg JR, Khavandi K, McCollum CN. Career choices in 21st-century healthcare: Aiming for a moving target. Int J Surg 2008; 6(6): 435-436.

3. Delamothe T. Modernising Medical Careers: final report. BMJ 2008; 336(7635): 54-55.

4. Abioye IA, Ibrahim NA, Odesanya MO, Wright KO. The future of trauma care in a developing country: Interest of medical students and interns in surgery and surgical specialties. Int J Surg 2012; 10(4): 209-212.

5. Hauer KE, Durning SJ, Kernan WN, Fagan MJ, Mintz M, O'Sullivan PS, et al. Factors associated with medical students' career choices regarding internal medicine. JAMA 2008; 300(10): 1154-1164.

6. Lefevre JH, Roupret M, Kerneis S, Karila L. Career choices of medical students: a national survey of 1780 students. Med Educ 2010; 44(6): 603-612.

7. Gelfand DV, Podnos YD, Wilson SE, Cooke J, Williams RA. Choosing general surgery: insights into career choices of current medical students. Arch Surg 2002; 137(8): 941-945; discussion 5-7.

8. Scott IM, Matejcek AN, Gowans MC, Wright BJ, Brenneis FR. Choosing a career in surgery: factors that influence Canadian medical students' interest in pursuing a surgical career. Can J Surg 2008; 51(5): 371-377.

9. Kozar RA, Anderson KD, Escobar-Chaves SL, Thiel MA, Brundage SI. Preclinical students: who are surgeons? J Surg Res 2004; 119(2): 113116.

10. Baxter N, Cohen R, McLeod R. The impact of gender on the choice of surgery as a career. Am J Surg 1996; 172(4): 373-376.

11. Azizzadeh A, McCollum CH, Miller CC, 3rd, Holliday KM, Shilstone HC, Lucci A, Jr. Factors influencing career choice among medical students interested in surgery. Curr Surg 2003; 60(2): 210-213.

12. Cochran A, Melby S, Neumayer LA. An Internet-based survey of factors influencing medical student selection of a general surgery career. Am J Surg 2005; 189(6): 742-746.

13. Yusufu LMD, Ameh EA, Wammanda RD, Odigie VI. Choice of specialty by preregistration House Officers. Nig J Surg 2004; 10(1): 8-10.

14. Griffen WO, Jr., Schwartz RW. Controllable lifestyle as a factor in choosing a medical career. Am J Surg 1990; 159(2): 189-190.

15. Lambert EM, Holmboe ES. The relationship between specialty choice and gender of U.S. medical students, 1990-2003. Acad Med 2005; 80(9): 797-802.

16. Buddeberg-Fischer B, Stamm M, Buddeberg C, Bauer G, Haemmig O, Knecht M, et al. The impact of gender and parenthood on physicians' careers - professional and personal situation seven years after graduation. $B M C$ Health Serv Res 2010; 10: 40.

17. Harrison RA, Gregg JL. A time for change: an exploration of attitudes toward part-time 
work in academia among women internists and their division chiefs. Acad Med 2009; 84(1): 8086.

18. Park J, Philipp R, Hughes A. Do we value work experience before medical school? $\mathrm{Br} J$ Gen Pract 2005; 55(512): 242-243.

19. Schwartz RW, Haley JV, Williams C, Jarecky RK, Strodel WE, Young B, et al. The controllable lifestyle factor and students' attitudes about specialty selection. Acad Med. 1990; 65(3): 207-210.
20. van der Horst K, Siegrist M, Orlow P, Giger M. Residents' reasons for specialty choice: influence of gender, time, patient and career. Med Educ 2010; 44(6): 595-602.

21. Lambert TW, Goldacre MJ, Turner G. Career choices of United Kingdom medical graduates of 2002: questionnaire survey. Med Educ 2006; 40(6): 514-521. 